\title{
Projector-based virtual reality dome environment for procedural pain and anxiety in young children with burn injuries: a pilot study
}

This article was published in the following Dove Press journal: Journal of Pain Research

\author{
Christelle Khadra, ${ }^{1,2}$ Ariane \\ Ballard, ${ }^{1,2}$ Johanne Déry, ${ }^{1,3}$ \\ David Paquin, ${ }^{4}$ Jean-Simon \\ Fortin, ${ }^{5}$ Isabelle Perreault, ${ }^{6}$ \\ David R Labbe, ${ }^{7}$ Hunter \\ G Hoffman, ${ }^{8}$ Stéphane \\ Bouchard, ${ }^{9}$ Sylvie LeMay ${ }^{1,2}$ \\ 'Faculty of Nursing, University of \\ Montreal, Montreal, QC, Canada; \\ ${ }^{2}$ Research Center, Centre Hospitalier \\ Universitaire (CHU) Sainte-Justine, \\ Montreal, QC, Canada; ${ }^{3}$ Direction \\ of Nursing, Centre Hospitalier \\ Universitaire (CHU) Sainte-Justine, \\ Montreal, QC, Canada; ${ }^{4}$ Department \\ in Creation and New Media, \\ Université du Québec en Abitibi- \\ Témiscamingue, Rouyn-Noranda, QC, \\ Canada; ${ }^{5}$ Emergency Department, \\ Hôpital de Granby, Granby, QC, \\ Canada; ${ }^{6}$ Department of Surgery, \\ Centre Hospitalier Universitaire \\ (CHU) Sainte-Justine, Montreal, QC, \\ Canada; ${ }^{7}$ Department of Software and \\ IT Engineering, École de Technologie \\ Supérieure, Montreal, QC, Canada; \\ ${ }^{8}$ Department of Mechanical \\ Engineering, University of Washington, \\ Seattle, WA, USA; ' $D$ Department of \\ Psychoeducation and Psychology, \\ Université du Québec en Outaouais, \\ Gatineau, QC, Canada
}

Correspondence: Sylvie LeMay Faculty of Nursing, Université de Montréal, PO Box 6128, Succursale Centre-Ville, Montreal H3C 3J7, QC, Canada

Tel +I 5 I4566 8892

$\mathrm{Fax}+\mathrm{I} 4506213960$

Email sylvie.lemay@umontreal.ca
Background: Virtual reality (VR) is a non-pharmacological method to distract from pain during painful procedures. However, it was never tested in young children with burn injuries undergoing wound care.

Aim: We aimed to assess the feasibility and acceptability of the study process and the use of VR for procedural pain management.

Methods: From June 2016 to January 2017, we recruited children from 2 months to 10 years of age with burn injuries requiring a hydrotherapy session in a pediatric university teaching hospital in Montreal. Each child received the projector-based VR intervention in addition to the standard pharmacological treatment. Data on intervention and study feasibility and acceptability in addition to measures on pain (Face, Legs, Activity, Cry, Consolability scale), baseline (Modified Smith Scale) and procedural (Procedure Behavior Check List) anxiety, comfort (OCCEB-BECCO [behavioral observational scale of comfort level for child burn victims]), and sedation (Ramsay Sedation Scale) were collected before, during, and after the procedure. Data analyses included descriptive and non-parametric inferential statistics.

Results: We recruited 15 children with a mean age of $2.2 \pm 2.1$ years and a mean total body surface area of $5 \%( \pm 4)$. Mean pain score during the procedure was low $(2.9 / 10, \pm 3)$, as was the discomfort level $(2.9 / 10, \pm 2.8)$. Most children were cooperative, oriented, and calm. Assessing anxiety was not feasible with our sample of participants. The prototype did not interfere with the procedure and was considered useful for procedural pain management by most health care professionals.

Conclusion: The projector-based VR is a feasible and acceptable intervention for procedural pain management in young children with burn injuries. A larger trial with a control group is required to assess its efficacy.

Keywords: pain, virtual reality, distraction, burns, preschool children, wound care

\section{Introduction}

Pediatric burns account for $30 \%-50 \%$ of total burns ${ }^{1,2}$ with the highest incidence occurring in young children under the age of five..$^{3-5}$ Pain management is a complex and crucial element of burn care in children. ${ }^{6}$ Procedural pain related to burn wound care is widely undertreated. ${ }^{7,8}$ Procedures related to dressing change and wound care have been described by children as "the most traumatizing and frightening part of their experience of having a burn". 9

Repeated exposure to painful stimuli, which is the case in burn wound care, can lead to pain centralization and higher incidence of persistent pain. ${ }^{10}$ Particularly at a young age, burn injuries may result in altered mechanical and pain sensitivity in later 
years of childhood, including long-term alterations in pain processing. ${ }^{11,12}$ Children also experience an anticipatory anxiety related to the unfamiliar environment, separation from parents, and fear of pain, which, in turn, can increase the amount of pain experienced. ${ }^{6,9,13}$ Physiological and behavioral responses to acute stress including posttraumatic stress symptoms and physiological reactivity have been observed in young children with burn injuries. ${ }^{14}$

Current management of procedural pain is mainly pharmacological, relying largely on opioids and nonopioid adjuncts. ${ }^{10,13,15}$ Analgesics, especially opioids, are associated with many side effects including respiratory depression, constipation, opioid-induced hyperalgesia, pruritus, sleep cycle interference, nausea, vomiting, and possible long-term development of tolerance with accompanying dose escalation and reward-based behavior to opiate medication. ${ }^{10,16,17}$ There is a need for methods that enhance pain control while reducing the side effects. Hence, there is an increasing interest in non-pharmacological methods as adjuncts to analgesics for optimal pain management. ${ }^{10}$

In children, non-pharmacological interventions for procedural pain management include, but are not limited to, music, guided imagery, toys, or video games, depending on the child's age, developmental stage, and the type of procedure. ${ }^{18,19}$ Distraction is often used with children as a non-pharmacological intervention for pain, distress, and anxiety. The assumption is that it diverts the child's attention to an attractive element, hindering the perception of the painful stimuli. ${ }^{19,20}$ This is based on the gate control theory of Melzack and Wall ${ }^{21}$ further extended by McCaul and Malott ${ }^{22}$ stating a link between perception of pain and level of attention devoted to the stimulus affecting the painful experience. ${ }^{19}$ Therefore, distraction techniques engaging multiple senses, such as vision and audition, may grab the child's attention more than the techniques that only engage one sense. Consequently, there is an increasing interest in more immersive and interactive methods of distraction, such as virtual reality (VR), for the management of procedural pain.

VR is defined as "a computer technology that enables users to view or immerse themselves in an alternate world". ${ }^{23}$ More specifically, it is a distraction method that provides the user with real-time interaction with computer-simulated entities in a pseudo-natural immersion via multisensory stimulation (vision, hearing, and sometimes touch) ${ }^{24-27}$ Fuchs $^{26}$ identifies immersion and interaction as key components of VR, while Vince ${ }^{28}$ and Aguinas et $\mathrm{a}^{23}$ add navigation in the virtual environment as a third component.
In the past two decades, VR has shown promising results for reducing experimental and procedural acute pain and burn-related discomfort in adolescents and adult burn victims. ${ }^{29-31} \mathrm{~A}$ laboratory functional magnetic resonance imaging brain scan study conducted by Hoffman et al with nine healthy subjects showed that the percentage of reduction in pain by VR was comparable to the effect of a moderate dose of hydromorphone equivalent to what a patient would receive during a burn wound care. ${ }^{32} \mathrm{~A}$ randomized controlled trial by Kipping et al ${ }^{33}$ among 41 adolescents with burn injuries compared VR to standard distraction during wound care procedures. Although no statistically significant difference was found in self-repoted pain scores between groups, less pain behaviors were observed by the nurses on the Face, Legs, Activity, Cry, Consolability (FLACC) scale. In addition, less rescue analgesia was recorded in the VR group compared to the standard distraction group. ${ }^{33}$ Another randomized controlled trial by Jeffs et $\mathrm{a}^{34}$ compared standard care, passive distraction (watching a movie), and VR among 28 adolescents (mean age of 13.5 years) from a burn clinic. The study showed that participants in the VR group reported less pain during burn wound care than either one of the two other groups as well as being the only group to have a decrease in pain perception from pre- to the per-procedural period. ${ }^{34} \mathrm{~A}$ rapid evidence assessment review by Garrett et $\mathrm{a}^{35}$ on the use of immersive VR in acute pain management emphasized its potential for burn injuries while highlighting the need for further high-quality studies to establish its effectiveness.

On the other hand, to our knowledge, VR for pain management in young children $(<4$ years old) has not been studied. Two studies reported the effects of VR on pain and coping styles in children as young as 6 years of age undergoing cold pressor pain. ${ }^{36,37}$ One study by Asl Aminabadi et a ${ }^{38}$ reported the effectiveness of VR distraction via eyeglasses on pain during dental treatment in 117 children from 4 to 6 years of age. However, no studies in children younger than 4 years old were retrieved.

In addition, currently available VR prototypes require wearing either goggles or a head-mounted display helmet to create a sense of space and depth. ${ }^{25}$ This could be challenging in young children with burn injuries, since most injuries at this age are located on the face and upper trunk. ${ }^{39}$ Our team tested a new way of delivering VR in clinical settings via a projector-based VR dome environment providing different levels of immersion that can also be added to the user's natural interaction in the real world while allowing for navigation and interaction with the virtual world, during burn wound care procedures in hydrotherapy in young children. 


\section{Aims}

In this pilot study, we aimed to assess the feasibility and acceptability of a projector-based VR dome environment as an intervention to distract young children with burn injuries from procedural pain and anxiety during hydrotherapy sessions. We also planned to evaluate the feasibility and acceptability of the study process including recruitment, choice of outcomes, and data collection methods prior to conducting a future large-scale/definitive trial on the efficacy of the proposed intervention on procedural pain and anxiety.

\section{Materials and methods Design and setting}

This single-center, one-group, quasi-experimental pilot study was approved by the Research and Ethics Board of the Centre Hospitalier Universitaire (CHU) Sainte-Justine and registered at clinicaltrials.gov (NCT02794103). Data were collected at CHU Sainte-Justine, a large pediatric tertiary university health center located in Montreal (Quebec, Canada). CHU Sainte-Justine is a major referral center for pediatric burns in the province of Quebec with more than 200 outpatients and 60-80 inpatients per year. All parents gave written informed consent to the participation of their child in the study. When possible, the child also gave his verbal consent prior to participating in the study. Health care professionals present in the hydrotherapy room provided permission for the images to be taken and used in publications. Parents of participating children were also given the option to consent for photographs and, when applicable, indicate whether or not they wish to preserve the anonymity of their child.

\section{Participants}

Participants were recruited through convenience sampling upon arrival to the surgical-trauma burn unit. The unit has a hydrotherapy room available for both inpatients and outpatients. Parents of a child with burn injuries, scheduled for a hydrotherapy session, were approached and provided with information about the study. Children were included in the study if they met the following criteria: 1) age from 2 months to 10 years (age limit was initially set from 6 months to 7 years; it was later modified to determine the age span that would most benefit from the projector-based VR dome environment) and 2) suffering from a burn injury (no limits regarding degree, depth, or extent of the burn injury). Children were excluded from the study if they were 1) admitted to the intensive care unit; 2) diagnosed with a neurocognitive disability precluding them from interacting with the distraction intervention; 3) intubated during hydrotherapy session; 4) suffering from epilepsy (considering the nature of the intervention); 5) allergic to opioids, other analgesics, or sedatives used as standard pharmacological treatment; and 6) had a sedation score of 6 on the Ramsay Sedation Scale (RSS; range between 1 and 6).

\section{Wound care procedures}

The hydrotherapy session during which the burn wounds are cleaned in water in addition to debriding the dead skin usually lasts between 20 and 40 minutes. It is considered a painful procedure as the child undergoes many physical manipulations including dressing removal, before getting in the hydrotherapy tank, then wound debridement, and rangeof-motion exercises in the tank before being transferred back to the stretcher for cultures and examination by general and plastic surgeons. Afterward, the nurse transfers the child to another room to apply the new dressing.

During the procedures, a nurse from the pain clinic monitors and documents the child's pain, with the anesthetist, to adjust the dosage of analgesics for the current session and subsequent hydrotherapy sessions, when applicable. Of note, parents are not allowed in the hydrotherapy room as the team has noticed from previous experiences that their presence increases both their child's and their own distress and anxiety.

\section{Standard care}

The standard care established in the institution by the pain clinic and the surgical trauma unit consists of pharmacological treatments combining opioids, non-opioid analgesics, and sedative agents. Doses are based on a preestablished protocol and adjusted by the anesthetist and the pain clinic nurse after assessing the child on the day of the scheduled procedure (hydrotherapy session). One hour before the procedure, the child receives the first dose of analgesia as follows: either oral morphine (starting dose: $0.4-0.5 \mathrm{mg} / \mathrm{kg}$ / dose) or oral hydromorphone (starting dose: $0.08-0.1 \mathrm{mg}$ / $\mathrm{kg} / \mathrm{dose}$ ), and oral clonidine (2-4 $\mu \mathrm{g} / \mathrm{kg} / \mathrm{dose}$, maximum of $100 \mu \mathrm{g})$. Thirty minutes prior to the procedure, the child receives oral ketamine $(5-10 \mathrm{mg} / \mathrm{kg} / \mathrm{dose}$, maximum of 500 $\mathrm{mg}$ ), oral midazolam $(0.2-0.5 \mathrm{mg} / \mathrm{kg} / \mathrm{dose}$, maximum of $20 \mathrm{mg})$, and oral acetaminophen $(10 \mathrm{mg} / \mathrm{kg} /$ dose, maximum of $640 \mathrm{mg}$ ). During the procedure, the child may receive a rescue analgesia, if required, consisting of intranasal fentanyl $(1 \mu \mathrm{g} / \mathrm{kg} / \mathrm{dose}$, maximum of $100 \mu \mathrm{g})$ every 5 minutes for a maximum of three doses. If the child has an intravenous access, he/she can instead receive either morphine $(0.025$ $0.05 \mathrm{mg} / \mathrm{kg} / \mathrm{dose})$ or hydromorphone $(0.01 \mathrm{mg} / \mathrm{kg} / \mathrm{dose})$ or midazolam $(0.05 \mathrm{mg} / \mathrm{kg} /$ dose, maximum three doses $)$. 


\section{Intervention}

A projector-based VR dome environment developed by Cobra Simulation ${ }^{\circledR}$ was adapted to the hydrotherapy room by the Society of Arts and Technology in Montreal. The dome consists of a $150^{\circ}$ wide curved screen installed at one end of the hydrotherapy tank. The screen is geared toward providing a certain level of immersion depending on the perceived sense of presence of the user. It does not require wearing a helmet or 3D glasses, therefore minimizing potential contamination between patients, but rather adds a natural social aspect to the environment where the procedure is taking place. It is operated by a projector (PANASONIC PT-RZ47, resolution: $1920 \times 1080)$ linked to a computer (Lenovo Y50-70, 2013, Version 1.0.0.52, Windows 8.1, Processor: Intel ${ }^{\circledR}$ Core $^{\mathrm{TM}} \mathrm{i} 7-4720 \mathrm{HQ}$, central processing unit (a) $2.60 \mathrm{GHz} 2.60 \mathrm{GHz}$, installed random-access memory: 16.0 GB, system type: 64-bit operating system, $\times 64$-based processor) with the software (video game). The video game Bubbles $^{\circledR}$ is a pseudo-3D game developed by our team with a level of difficulty tailored to the young child's developmental stage, allowing control over its components (speed, visual yaw rotation, and vection [visually induced sense of self-motion $\left.{ }^{40}\right]$ ), to attenuate cybersickness symptoms such as nausea and vomiting.

The game is turned on the moment the child is installed in the hydrotherapy tank. Depending on his age and sedation level, the child can generate extra bubbles, on the screen, by squeezing a waterproof, pear-shaped mouse. If the child is too young to understand how to use the mouse or if the burn injury is located on his hands, a proxy, usually the research nurse or the nurse from the pain clinic, will squeeze the mouse to produce extra bubbles. Friendly shaped animals appear on the screen and produce funny noises and facial expressions whenever they are hit by a bubble while the child is navigating on a wagon train through different sceneries (village, beach, forrest). Bubbles are also be generated automatically after 30 seconds of inactivity to maintain interaction within the game. A joyful musical track is also part of the video. The game was tested and approved by a team of health care professionals (nurses, physiotherapists, plastic surgeon, clinical nurse specialist) involved in pediatric burn care prior to its use with children. The dome and game are shown in Figures 1 and 2 , respectively.

\section{Data collection/study time periods}

The experiment consisted of one session per participant with measures taken at five time periods: 1 hour before the

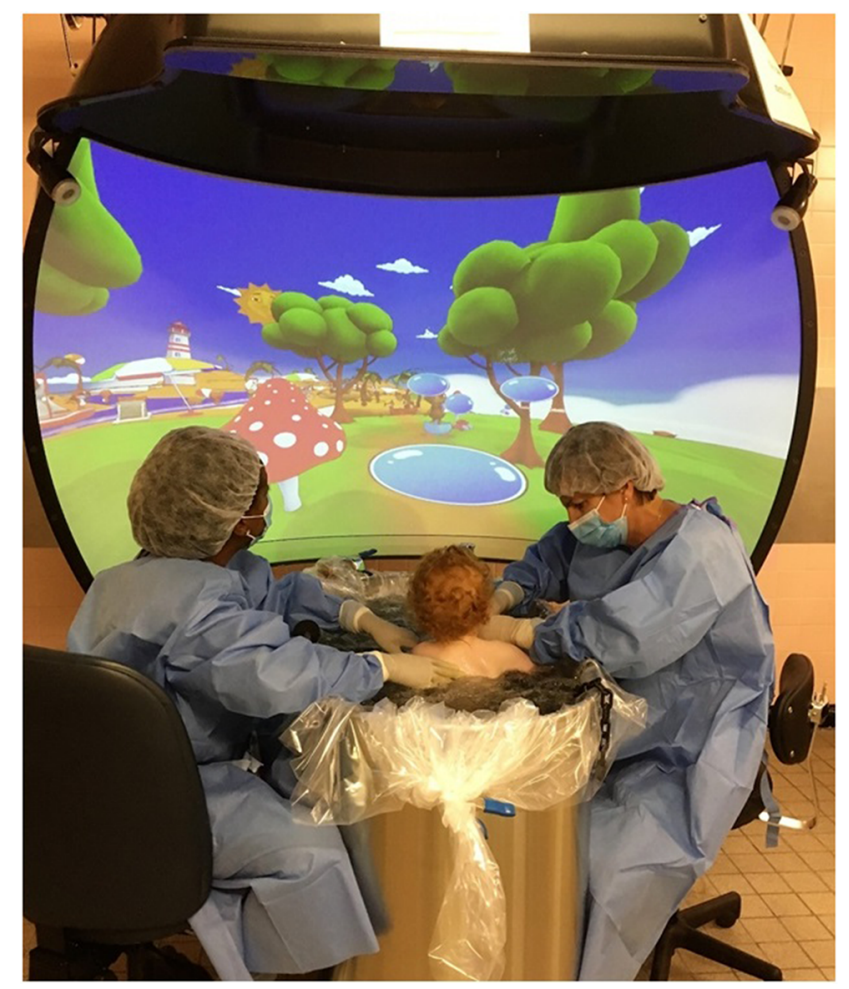

Figure I Virtual reality prototype at the hydrotherapy room of CHU Sainte-Justine. Abbreviation: $\mathrm{CHU}$, Centre Hospitalier Universitaire.

procedure (T1), on arrival at the hydrotherapy room (T2), 10 minutes after the beginning of the procedure (concurrent with debridement; T3); immediately after the procedure and before leaving hydrotherapy room (T4); and 30 minutes after the procedure (T5). However, to be able to assess the feasibility of the intervention with repeated exposures, each recruited patient was offered the projector-based VR intervention for subsequent hydrotherapy sessions when applicable. Nevertheless, only the first session was accounted for in the clinical outcomes analysis (pain, anxiety, comfort).

\section{Measures}

The following measures were used to describe the sample, to assess the feasibility and acceptability of the projector-based VR intervention and the study design, ${ }^{41}$ in addition to reporting data on pain, anxiety, comfort, and sedation.

\section{Sociodemographic and clinical questionnaire}

Demographic and clinical characteristics were assessed with parent reports and hospital chart review filled out by the research nurse. The questionnaire also included a section on the procedure's characteristics including the dosage of each drug administered, use of other non-pharmacological intervention, and requirements for rescue analgesia. 


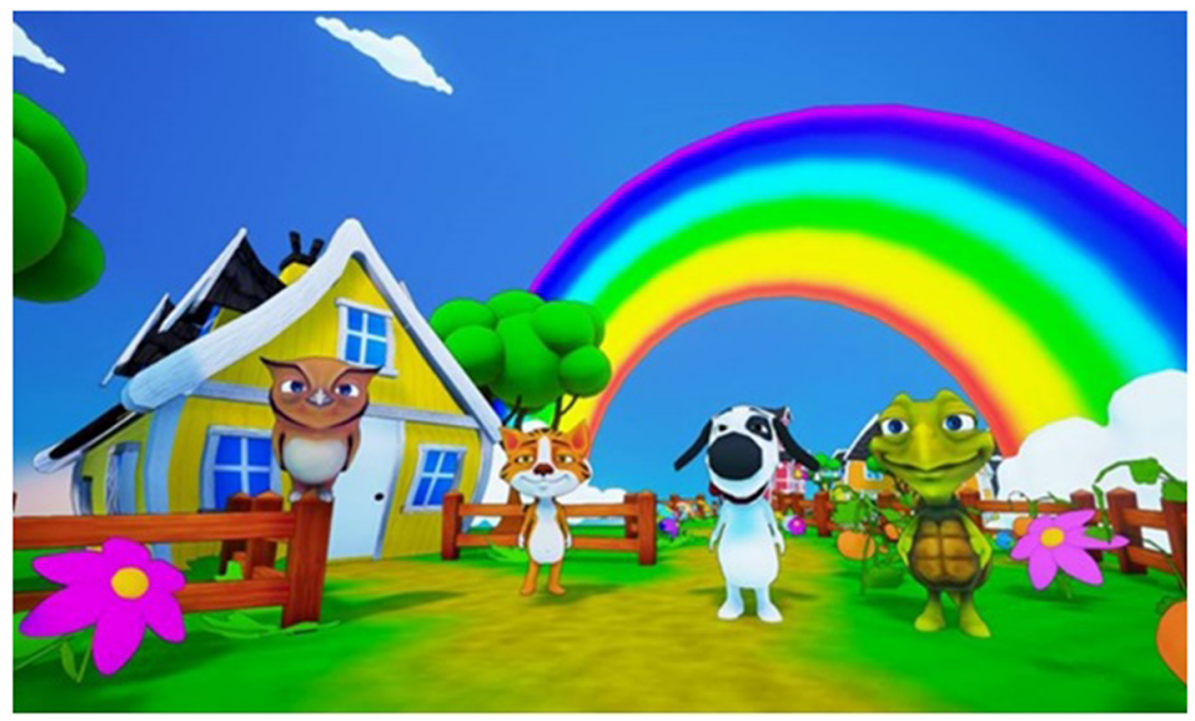

Figure 2 Screenshot of the video game Bubbles@ .

Note: Image courtesy of Oniric-Interactive, Inc. Available from: http://www.oniric-interactive.com/. Accessed January 3, 2018. . 2016 Oniric-Interactive, Inc.

\section{Feasibility and acceptability of the VR intervention} Intervention feasibility outcomes included proper functioning of the game and the projector-based VR dome environment (protoype), as well as coordination of the delivery of the intervention (Cobra dome) with the wound care procedure. Intervention acceptability was assessed by asking health care professionals to rate, after each procedure, the extent to which they agreed or disagreed (four choices response scale from strongly agree to strongly disagree) with eight items related to their level of satisfaction with the projector-based VR intervention, prototype, and video game, that is, use of the intervention for the purposes of distraction, interference with the procedure, adaptation of the prototype to the hydrotherapy room setting, perceived effect on the child's pain and cooperation, appropriateness of the game for the age of the participants, their willingness to reuse the prototype in future procedures, and whether or not they considered the projector-based VR distraction an idea worth developing. The questionnaire was pretested with two health care professionals with experience in pediatric pain and burn injuries/ hydrotherapy procedure, and the questions were specific to the projector-based VR distraction for children undergoing hydrotherapy sessions for burn wound care. Finally, the occurrence of side effects resulting from the projector-based VR intervention was documented.

\section{Feasibility and acceptability of the study process}

Feasibility of the study process was assessed by documenting the following outcomes: number of eligible patients during the study period, percentage of eligible patients/parents agreeing to participate in the study (recruitment feasibility), appropriateness of the inclusion and exclusion criteria, appropriateness, timing, and sequencing of study measures, in addition to the selection of best outcome measures. Acceptability was assessed by determining the willingness of parents/children to receive the projector-based VR intervention in subsequent hydrotherapy sessions.

\section{Clinical outcomes}

1. Pain intensity was measured at all study time points ( $\mathrm{T} 1$ to T5) using the FLACC scale, a behavioral/observational pain scale from 0 to 10 ( $0=$ relaxed and comfortable, $7-10=$ severe discomfort/pain) for children from 0 to 18 years old. ${ }^{42}$

2. Baseline anxiety was assessed at T1 using the Modified Smith Scale, a behavioral/observational scale with four levels ranging from 0 (no anxiety) to 3 (most anxious) ${ }^{43,44}$

3. Procedural anxiety and distress were assessed at $\mathrm{T} 2, \mathrm{~T} 3$, T4, and T5 using the Procedure Behavior Check List (PBCL) scale which comprises eight behaviors based on occurrence and intensity for a possible total score ranging from 0 to $40 . .^{45}$

4. Comfort during the procedure was assessed at T3 using the behavioral observational scale of comfort level for child burn victims (OCCEB-BECCO [behavioral observational scale of comfort level for child burn victims]), a new observational scale with scores ranging from 0 to 10 developed by members of our team, specifically for children during hydrotherapy procedures. ${ }^{46}$ 
5. Levels of sedation were also assessed before, during, and after the procedure (T2, T3, T4) via the RSS ranging from 1 (anxious or restless or both) to 6 (no response to stimulus). Finally, sociodemographic and clinical data were collected and the need for rescue medication administered during the procedure was documented.

\section{Sample size}

As the current trial is a pilot study, a sample size calculation (prestudy power calculation) was not performed. Instead, we aimed to recruit 15-20 children as this number would be adequate to provide information regarding feasibility of the intervention and study process/measures.

\section{Data analyses}

As this is a pilot study, the analyses were mainly descriptive. ${ }^{47}$ Analyses were conducted using the statistical analysis software SPSS version 24.0 (IBM Corporation, Armonk, NY, USA). Given the small sample size, non-parametric measures were used. Mean pain differences with repeated pain and anxiety measures using, respectively, the FLACC and the PBCL before, during, and after the procedure were calculated using Freidman tests with $P<0.05$ considered to be the statistically significance threshold. However, the results were interpreted with caution because of the small sample size. A Spearman's rank correlation was also run to determine the strength of the relationship between pain and anxiety at $\mathrm{T} 3$.

Three out of eight behaviors assessed by the PBCL regarding pain verbalization, anxiety verbalization, and verbal stalling were not possible to measure in preverbal children. This resulted in item-level missing data for some participants. As the PBCL is intended to be used, as a whole, to measure the construct of medical procedure-related/painrelated anxiety, and given the small sample size, no imputation method was used to replace missing responses, and the score was, therefore, treated as missing.

\section{Results}

\section{Sample characteristics}

Data were collected from June 14, 2016, to January 31, 2017. During the recruitment period, 19 parents of children meeting the selection criteria were invited to participate in the study. Only one couple refused their child's participation due to cultural issues. The recruitment rate was, therefore, $95 \%$. Of the 18 patients recruited, 3 were excluded because they were highly sedated during the hydrotherapy session, which prevented reliable measurements of pain and anxi- ety. Analyses were conducted on a total sample size of 15 children.

Table 1 presents the sociodemographic and clinical characteristics of the children, including information on burn injuries, previous pain experiences, and baseline anxiety. Mean age of participants was 2.2 years \pm 2.1 (median $[\mathrm{Mdn}]=1.6$; interquartile range $[\mathrm{IQR}]=0.9-2.4)$, with the majority being boys (60\%). All burns, except one, were caused by a thermal injury $(93.3 \%)$ with a mean total body surface area of $5 \%$ $( \pm 4)$. Most children $(86.6 \%)$ had low baseline anxiety levels (level 0 or 1 on the Smith Modified Anxiety scale) before the procedure $(\mathrm{Mdn}=0 ; \mathrm{IQR}=0.0-1.0)$.

Table I Participants' characteristics

\begin{tabular}{|c|c|}
\hline Characteristics & $\mathbf{N}=\mathbf{I} \mathbf{5}$ \\
\hline \multicolumn{2}{|l|}{ Sex, n (\%) } \\
\hline Girls & $40(6)$ \\
\hline Boys & $60(9)$ \\
\hline \multicolumn{2}{|l|}{ Ethnicity, n (\%) } \\
\hline Caucasian & $86.7(13)$ \\
\hline Other & $13.3(2)$ \\
\hline Age (years $\pm S D)$ & $2.2 \pm 2.1$ \\
\hline Weight (kg士SD) & $13.5 \pm 9.9$ \\
\hline \multicolumn{2}{|l|}{ Previous hospitalization, n (\%) } \\
\hline Yes & $26.7(4)$ \\
\hline No & $73.3(I I)$ \\
\hline \multicolumn{2}{|c|}{ Previous experience of procedural pain excluding vaccination, $n(\%)$} \\
\hline Yes & $33.3(5)$ \\
\hline No & $66.7(10)$ \\
\hline \multicolumn{2}{|l|}{ Medical and surgical history, $\mathrm{n}(\%)$} \\
\hline Yes & $40(6)$ \\
\hline No & $60(9)$ \\
\hline \multicolumn{2}{|l|}{ Causes of burns, $\mathrm{n}(\%)$} \\
\hline Thermal & $93.3(14)$ \\
\hline Chemical & $6.7(1)$ \\
\hline Electrical & $0(0)$ \\
\hline \multicolumn{2}{|l|}{ Burn types, n (\%) } \\
\hline Superficial (first degree) & $6.7(1)$ \\
\hline Superficial partial thickness (second degree) & $13.3(2)$ \\
\hline Deep partial thickness (second degree) & $53.3(8)$ \\
\hline Full thickness (third degree) & $20(3)$ \\
\hline Fourth degree & $0(0)$ \\
\hline Extent of the burns $(\% T B S A \pm S D)$ & $5 \pm 4$ \\
\hline Mean number of days since the injury (days $\pm S D$ ) & $4.5 \pm 3.7$ \\
\hline \multicolumn{2}{|c|}{ Number of hydrotherapy sessions before enrollment in the study, $\mathrm{n}(\%)$} \\
\hline None & $73.3(11)$ \\
\hline One session & $13.3(2)$ \\
\hline Two sessions & $6.7(1)$ \\
\hline Three sessions & $6.7(1)$ \\
\hline \multicolumn{2}{|l|}{ Baseline anxiety (Modified Smith Scale), n (\%) } \\
\hline Anxiety level 0 & $53.3(8)$ \\
\hline Anxiety level I & $33.3(5)$ \\
\hline Anxiety level 2 & $6.7(1)$ \\
\hline Anxiety level 3 & $6.7(1)$ \\
\hline
\end{tabular}

Abbreviation: TBSA, total body surface area. 


\section{Characteristics related to the procedure}

On average, hydrotherapy sessions lasted 18.4 minutes $( \pm 4.4$ minutes). In all but two sessions, wound debridement was conducted. Range-of-motion exercises were performed in 11 sessions ( $73.3 \%$ ). During 9 out of 15 sessions (60\%), other non-pharmacological interventions were used for pain or anxiety, including pacifiers, touch, singing, and plastic bath toys. Only 3 children out of 15 (20\%) required additional rescue analgesia during the hydrotherapy session.

\section{Feasibility and acceptability of the VR intervention}

During the first month of the trial, developers were notified about two technical issues that occurred within the game. The technical issues were fixed in the following week and no other problems occurred afterward. A headlight was provided to health care professionals, when needed, as the hood of the dome could slightly reduce the lighting inside the hydrotherapy tank. Otherwise, the prototype did not interfere with wound care procedures as health care professionals were able to carry out their activities as usual.

More than two-thirds (68.7\%) of responses from health care professionals indicated satisfaction with the use of the projector-based VR dome environment during the hydrotherapy session. Health care professionals considered that the intervention allowed the child to better cooperate with care $55.6 \%$ of the time and helped control the pain $68.7 \%$ of the time. The majority (85.9\%) indicated that the intervention did not interfere with the course of treatment/care and $91.3 \%$ considered that the prototype was adapted to the setting of the hydrotherapy room as well as to the age of the child (90.2\%). Finally, everyone (100\%) indicated that they would use the projector-based VR distraction again for future burn wound care in children and that it is an intervention worth developing.

As for side effects, only one child vomited following the hydrotherapy session, but the vomiting did not seem related to the projector-based VR dome environment as the child also vomited prior to the beginning of the procedure. Therefore, it might be more related to the analgesics administered prior to the hydrotherapy session rather than to the VR intervention.

\section{Feasibility and acceptability of the study process}

The youngest child/infant recruited was 3 months old and was the only participant younger than 6 months old. She did not interact with the animals in the game and was rather more interested and distracted by plastic toys. The second youngest child/infant was 8 months old and seemed to enjoy the game and benefit from the intervention as the observed pain score on the FLACC scale was $0 / 10$ during the procedure. Only one child participating in the study was older than 7 years (9 years old). Although this child enjoyed the game and interacted greatly with it, she was sitting on the edge of the stretcher, and not inside the hydrotherapy tank, with only her feet in the water because of her height and site of injury.

As for the timing of the measures, all study time periods were feasible except $\mathrm{T} 5$, as only 3 out of 15 participants were awake at this time point, making it difficult to collect a reliable measure of pain and anxiety. Regarding outcome measures, pain and comfort were feasible measures, but not anxiety given that most participants were too young to verbalize their anxiety. Sedation was measured using the RSS. Although this measure was feasible, the research nurse collecting the data noted that it did not seem to be sensitive enough to detect differences in procedural sedation of this group of children.

Finally, although not all children required more than one hydrotherapy session, all parents of participating children agreed to repeat the experience with the projector-based VR dome environment if ever their child required another session. Children who received the projector-based VR dome evironment for more than one session seemed to have a sustained interest that did not decrease from one session to another.

\section{Clinical outcomes}

Results related to pain and anxiety during the study are presented in Tables 2 and 3, respectively. There was not a statistically significant difference in observed pain on the FLACC scale before (T2), during (T3), and after (T4) the procedure $\left(\chi^{2}(2)=2.7, P=0.264\right)$. Mean pain score at T3 remained low (2.9/10 \pm 3.0$)$. However, pain levels' distribution on the FLACC scale was bimodal at T3 with participants presenting either low $(0-3 / 10)$ or severe $(\geq 7 / 10)$ pain scores (Mdn of 2.0; IQR=7.0-0.0; Figure 3).

Table 2 Pain scores at each study time

\begin{tabular}{llllll}
\hline Study time & $\begin{array}{l}\text { Participants } \\
\text { (n) }\end{array}$ & Minimum & Maximum & \multicolumn{2}{l}{ Mean/I 0* SD } \\
\hline FLACC_TI & 14 & 0 & 6 & 2.0 & 2.4 \\
FLACC_T2 & 15 & 0 & 7 & 2.1 & 2.7 \\
FLACC_T3 & 15 & 0 & 7 & 2.9 & 3.0 \\
FLACC_T4 & 14 & 0 & 8 & 2.6 & 2.9 \\
FLACC_T5 & 3 & 0 & 3 & 1.0 & 1.7 \\
\hline
\end{tabular}

Notes: $\mathrm{T} I=\mathrm{I}$ hour before the procedure; $\mathrm{T} 2=$ on arrival at the hydrotherapy room; $\mathrm{T} 3=10$ minutes after the beginning of the procedure (concurrent with debridement); $\mathrm{T} 4=$ immediately after the procedure and before leaving hydrotherapy room; $\mathrm{T} 5=30$ minutes after the procedure. $*$ Mean/ 10 refers to the mean pain score of participants at each study time on the FLACC scale ranging from 0 to 10 .

Abbreviation: FLACC, Face, Legs, Activity, Cry, Consolability scale. 
Table 3 Procedural anxiety scores at each study time

\begin{tabular}{llllll}
\hline Study time & $\begin{array}{l}\text { Participants } \\
\text { (n) }\end{array}$ & & Minimum & Maximum & Mean/40* \\
& SD \\
\hline PBCL_T2 & 7 & 8 & 30 & 14.0 & 9.4 \\
PBCL_T3 & 7 & 7 & 20 & 11.7 & 5.6 \\
PBCL_T4 & 7 & 7 & 22 & 12.3 & 6.0 \\
PBCL_T5 & 2 & 8 & 8 & 8.0 & 0.0 \\
\hline
\end{tabular}

Notes: $\mathrm{T} 2=$ on arrival at the hydrotherapy room; $\mathrm{T} 3=10$ minutes after the beginning of the procedure (concurrent with debridement); T4= immediately after the procedure and before leaving hydrotherapy room; $T 5=30$ minutes after the procedure. *Mean/40 refers to the mean anxiety of participants at each study time on the PBCL scale ranging from 8 to 40 .

Abbreviation: PBCL, Procedure Behavior Check List.

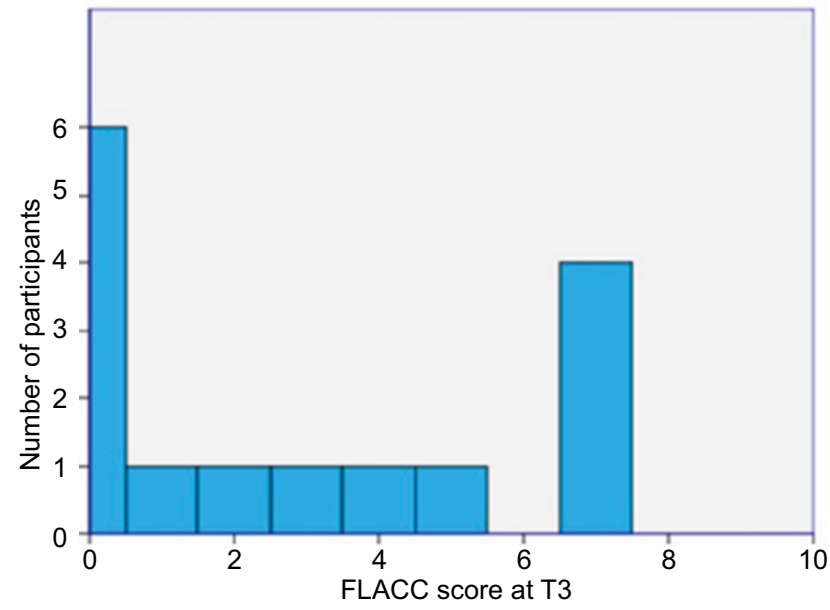

Figure 3 Distribution of pain scores during the wound care procedure (T3). Note: $\mathrm{T} 3=10$ minutes after the beginning of the procedure (concurrent with debridement).

Abbreviation: FLACC, Face, Legs, Activity, Cry, Consolability sacle.

The average level of anxiety as measured with the PBCL was also low at $\mathrm{T} 3$ with a mean score of $11.4 \pm 5.1$ over a maximum score of 40 . There was no statistically significant difference in procedural anxiety level among participants between the three procedure-related time periods (T2, T3, and T4; $\left.\chi^{2}(2)=0.4, P=0.827\right)$. There was a strong positive correlation between pain and procedural anxiety at $\mathrm{T} 3$, which was statistically significant $\left(r_{\mathrm{s}}(5)=0.811, P=0.027\right)$.

The mean comfort level at T3 was 2.9/10 $( \pm 2.8)$ on the OCCEB-BECCO. Most children were cooperative, oriented, and calm during the procedure with an Mdn sedation score of 2 (IQR=4.5-1; min. 1-max. 5) at T2, Mdn score of 2 (IQR=3.5-1; min. 1-max. 6) at T3, and Mdn score of 2 (IQR=3.5-1; min. 1-max. 5) at T4 on the RSS.

\section{Discussion}

Pain related to burn wound care procedures is very complex and challenging. ${ }^{16,48}$ Our pilot study showed that the projectorbased VR dome environment is a feasible intervention that could be used in children with burn injuries in addition to standard pharmacological treatment. Further, health care professionals were very satisfied and interested to use this type of technology in combination with analgesics for procedural pain management of children with burn injuries. To our knowledge, this is the first study using a projector-based VR dome in children younger than 4 years of age.

Efficacy of the projector-based VR dome environment for pain management could not be established in this pilot study without a control group and a larger sample size. Nevertheless, pain levels remained low during wound debridement, which is a short but very painful procedure and is known as the most distressing phase of wound care. ${ }^{10,49}$ The purpose was not to achieve lower pain scores at T3 than at $\mathrm{T} 1$ or $\mathrm{T} 2$, but rather to maintain a low pain level throughout the hydrotherapy session. A recent observational study by van der Heijden et al ${ }^{50}$ measured pain intensity and distress using the COMFORT Behavioral scale during burn wound care procedures without distraction or parental presence in 124 children from 0 to 13 years of age (Mdn age 21.2 months [IQR=14.9-39.5 months]). The study showed that $62 \%-89 \%$ of children experienced severe pain and distress, and $11 \%-31 \%$ of children experienced moderate pain and distress, with the most severe pain being measured in $89 \%$ of the children during the phase of the wound care where the wound was washed. ${ }^{50}$ The authors also found a correlation between age and COMFORT Behavioral scale scores, indicating that age was a predictor of pain intensity and distress, as younger children tended to have higher pain and distress scores than older children $(P<0.001)$. In our pilot study, the mean pain score on the FLACC was 2.9/10 $( \pm 3.0)$ indicative of a low pain level.

However, a bimodal distribution was observed at $\mathrm{T} 3$ with children experiencing either very low levels of pain or severe levels of pain on the FLACC scale. More specifically, the observed pain level was low in $60 \%(\mathrm{n}=9)$ of children ( $0-3 / 10$ on the FLACC scale), moderate (4-6/10 on the FLACC scale) in $13.3 \%(n=2)$ of children, and severe $(\geq 7 / 10$ on the FLACC scale) in $26.7 \%(n=4)$ of children. Although pain-attention interactions could help interpret this result as they characterize individuals as A-type (attention dominates) or P-type (pain dominates) ${ }^{51,52}$ and, therefore, would explain why some individuals may benefit from VR distraction, while others would not (opposing levels of pain), it is not possible to attribute it to the intervention without comparing both interventions in the same treatment session for the same patient.

The study process was deemed feasible. However, some challenges were observed regarding one of the study time points. Measurement at T5 was intended to observe any outlasting effect of the projector-based VR dome environ- 
ment. However, only 3 out of 15 patients were awake at this time period, making it impossible for data collection. In fact, after hydrotherapy, children are transferred to another room for wound dressing. Afterward, they are transferred again to their room (T5), and at that time, they are often tired and asleep, especially with the cumulative effects of both sedation and analgesics.

Also, the PBCL scale which comprises items requiring verbalization was not a feasible measure in preverbal children in the context of the current study, although the age range of studies which used this scale was $0.1-19$ years. ${ }^{53}$ In addition, assessing anxiety as such is a debated topic in pediatric pain, mainly in infants and preverbal children. Measures of distress and pain at this age range are observational and there is a considerable overlap between behaviors indicating pain, fear, or distress, making it very difficult to discriminate between pain-related and non-pain-related distress. ${ }^{54,55}$ This could explain the highly positive correlation between the FLACC and the PBCL at T3. Also, infants and young children do not have the same cognitive-emotional capabilities as older children or adults, and therefore, might not be able to differentiate between pain and anxiety. Their emotional development, however, is built in response to their early experiences and the caregivers' responses during infancy. ${ }^{56}$

Also, regarding the feasibility of measures, although the RSS was feasible in a sense that it gave a general idea about the level of sedation of participants, it was not specific enough for this type of procedure to detect subtle differences. For instance, a child could be responsive to commands (RSS 3) while being anxious without being agitated or restless (RSS 1), or could be sedated without brisk responses to stimuli (RSS 4) but not necessarily having a sluggish response to stimuli (RSS 5). Consequently, another sedation scale validated in children and validated for medical procedures, such as the University of Michigan Sedation scale, ${ }^{57}$ would probably be more appropriate for future studies with this population.

Regarding the study design, a better approach for future trials would be to compare the two treatment conditions (projector-based VR dome environment vs no VR/standard treatment) within the same hydrotherapy session and not between sessions or using a parallel design. This is because many children did not require another hydrotherapy session. In addition, we noted a high variability of sedation and pain responses from one session to another, despite the children receiving the same analgesia and the same projector-based VR intervention, due to other wound care procedures and skin grafts in some instances that added to the preexisting variability related to the burn site, depth, and extent. The within-subject design has been already adopted by some researchers in assessing the effect of VR in pediatric (6-19 years old) and adult patients, as each participant can serve as his own control within the same hydrotherapy session, decreasing procedural and personal variability. ${ }^{58,59}$

The age range in the inclusion criteria for this pilot trial was rather large (from 2 months to 10 years) in order to determine which age would most benefit from the projectorbased VR intervention. Based on observations, children younger than 6 months seemed to be more easily distracted with simple toys than with the dome environment. On the other hand, children older than 7 years, although were interested in the intervention, could not fit in the hydrotherapy tank where the prototype is fixed, and therefore, could not experience immersion.

It is acknowledged that this small-scale pilot study has some limitations. First, blinding of participants, health care professionals, and research team was not possible due to the nature of the intervention. In addition, it was very difficult to standardize the pharmacological treatment from one session to another. Although patients received the treatment according to a preestablished protocol, the doses could be adjusted by the pain clinic if they felt that the child was too anxious or distressed before the procedure. Moreover, the same analgesics could have different effects among patients or even with the same patient from one session to another, creating high heterogeneity in sedation levels and analgesia. On the other hand, the burn surface area was mostly small (mean total body surface area $=5 \% \pm 4 \%$ ), limiting the findings within this population. It is difficult to predict how children with more extensive burns would react to an intervention using distraction or whether they would be able to interact with a videogame as they might require a higher level of sedation during the procedure. Finally, given the young age of the participants, it was not possible to measure the sense of presence in infants and young children. The sense of presence is related to immersion and is an essential component of VR distraction that distinguishes it, along with interaction, from other forms of distraction such as playing video games or watching a television screen. ${ }^{60,61}$ As the sense of presence is usually assessed through self-report, we could know neither whether the immersion into the virtual world was successful or not, nor its extent.

\section{Conclusion}

VR distraction seems to be a promising venue as a nonpharmacological intervention in children. Our study has 
shown the feasibility and acceptability of a projector-based VR dome environment in young children with burn injuries. A larger, within-subject trial would be required to confirm the efficacy of this intervention for procedural pain management in the same population. Data from a larger sample would also allow to investigate the relationship and interaction of possible covariates that could mitigate pain levels, such as previous pain experiences, burn depth, and extent, among others.

\section{Acknowledgments}

The authors would like to thank Ms Lucie Farmer, Mr Daniel Jeté, Ms France Perron, Ms Viviane Tremblay, Mrs Sylvie Charette, the surgical-trauma team of the CHU SainteJustine, and Dr Edith Villeneuve, head of the pain clinic at the CHU Sainte-Justine for their great collaboration, as well as the children and their families for participating in the study. The authors also thank Mr Erwan Davisseau, Mr Eric Bisson Corriveau, Mr Matthieu Pesant, and Mr Simon Descôteaux for their work on the game Bubbles ${ }^{\odot}$, Mr Alexander Bradley, Managing Director at Cobra Simulation Limited ${ }^{\circledR}$ for his assistance and technical support for the Cobra screen, and the Society for Arts and Technology represented by Dr Patrick Dubé for adapting the prototype to the hydrotherapy room.

This project is supported by grants from the Direction of Nursing of CHU Sainte Justine, the Quebec Network on Nursing Intervention Research, the surgical-trauma program of CHU Sainte-Justine, the Centre d'expertise pour les Victimes de Brûlures Graves de l'Ouest du Québec (Fondation des Pompiers), the Patients/Parents committee of the CHU Sainte-Justine, the CHU Sainte-Justine's Foundation, in addition to NIH grants to David Patterson R01GM042725, R01AR054115, and Effat University, Jeddah Saudi Arabia Research and Consultancy Institute. CK is supported by the Canadian Institutes of Health Research, the Fonds de Recherche du Québec-Santé, and the Quebec Nursing Intervention Research Network. Authors CK, SLM, and $A B$ are members of Pain In Child Health, a strategic research training initiative of the Canadian Institutes of Health Research.

\section{Disclosure}

JSF is the founder of Oniric Interactive ${ }^{\odot}$, the company that developed the game Bubbles ${ }^{\odot}$. The authors report no other conflicts of interests in this work.

\section{References}

1. American Burn Association. 2016 National Burn Repository: Report of data from 2006-2015. 2016.
2. Brusselaers N, Monstrey S, Vogelaers D, Hoste E, Blot S. Severe burn injury in Europe: a systematic review of the incidence, etiology, morbidity, and mortality. Crit Care. 2010;14(5):R188.

3. Toon MH, Maybauer DM, Arceneaux LL, et al. Children with burn injuries-assessment of trauma, neglect, violence and abuse. J Inj Violence Res. 2011;3(2):98-110.

4. D'Souza AL, Nelson NG, McKenzie LB. Pediatric burn injuries treated in US emergency departments between 1990 and 2006. Pediatrics. 2009;124(5):1424-1430.

5. Verey F, Lyttle MD, Lawson Z, Greenwood R, Young A. When do children get burnt? Burns. 2014;40(7):1322-1328.

6. Krishnamoorthy V, Ramaiah R, Bhananker SM. Pediatric burn injuries. Int J Crit Illn Inj Sci. 2012;2(3):128-134.

7. de Jong AEE, Bremer M, van Komen R, et al. Pain in young children with burns: extent, course and influencing factors. Burns. 2014;40(1):38-47.

8. Latarjet J. The management of pain associated with dressing changes in patients with burns. EWMA J. 2002;2(2):5-9.

9. McGarry S, Elliott C, McDonald A, Valentine J, Wood F, Girdler S. Pediatric burns: From the voice of the child. Burns. 2014;40(4):606-615.

10. Retrouvey H, Shahrokhi S. Pain and the thermally injured patient - a review of current therapies. J Burn Care Res. 2015;36(2):315-323.

11. Grunau RE. Long-term effects of pain in children. In: McGrath PJ, Stevens BJ, Walker SM, Zempsky WT, editors. Oxford Textbook of Pediatric Pain. Oxford: Oxford University Press; 2014.

12. Wollgarten-Hadamek I, Hohmeister J, Demirakca S, Zohsel K, Flor H, Hermann C. Do burn injuries during infancy affect pain and sensory sensitivity in later childhood? Pain. 2009;141(1-2):165-172.

13. Norambuena C, Yañez J, Flores V, Puentes P, Carrasco P, Villena R. Oral ketamine and midazolam for pediatric burn patients: a prospective, randomized, double-blind study. J Pediatr Surg. 2013;48(3):629-634.

14. Stoddard FJ, Ronfeldt H, Kagan J, et al. Young burned children: the course of acute stress and physiological and behavioral responses. $\mathrm{Am}$ J Psychiatry. 2006;163(6):1084-1090.

15. Gamst-Jensen H, Vedel PN, Lindberg-Larsen VO, Egerod I. Acute pain management in burn patients: appraisal and thematic analysis of four clinical guidelines. Burns. 2014;40(8):1463-1469.

16. Thompson EM, Andrews DD, Christ-Libertin C. Efficacy and safety of procedural sedation and analgesia for burn wound care. J Burn Care Res. 2012;33(4):504-509.

17. Holtman JR Jr, Jellish WS. Opioid-induced hyperalgesia and burn pain. J Burn Care Res. 2012;33(6):692-701.

18. Olsen K, Weinberg E. Pain-less practice: techniques to reduce procedural pain and anxiety in pediatric acute care. Clin Pediatr Emerg Med. 2017;18(1):32-41.

19. Koller D, Goldman RD. Distraction techniques for children undergoing procedures: a critical review of pediatric research. J Pediatr Nurs. 2012;27(6):652-681.

20. Kleiber C, McCarthy AM. Evaluating instruments for a study on children's responses to a painful procedure when parents are distraction coaches. J Pediatr Nurs. 2006;21(2):99-107.

21. Melzack R, Wall PD. Pain mechanisms: a new theory. Science. 1965;150(3699):971-979.

22. McCaul KD, Malott JM. Distraction and coping with pain. Psychol Bull. 1984;95(3):516-533.

23. Aguinas H, Henle CA, Beaty JC Jr. Virtual reality technology: a new tool for personnel selection. Int J Sel Assess. 2001;9(1-2):70-83.

24. Hoffman HG, Chambers GT, Meyer WJ 3rd, et al. Virtual reality as an adjunctive non-pharmacologic analgesic for acute burn pain during medical procedures. Ann Behav Med. 2011;41(2):183-191.

25. Malloy KM, Milling LS. The effectiveness of virtual reality distraction for pain reduction: a systematic review. Clin Psychol Rev. 2010;30(8): 1011-1018.

26. Fuchs $P$. Virtual reality headsets - a theoretical and pragmatic approach. Leiden: CRC Press; 2017.

27. Fuchs P, Moreau G, Berthoz A, Vercher J-L, d'Aubert F. Le traité de la réalité virtuelle. Volume 1 - L'homme et l'environnement virtuel. Paris: Presses de l'Ecole des Mines; 2006. 
28. Vince J. Essential Virtual Reality Fast: How to Understand the Techniques and Potential of Virtual Reality. London: Springer; 1998.

29. Hoffman HG, Meyer WJ 3rd, Ramirez M, et al. Feasibility of articulated arm mounted Oculus Rift Virtual Reality goggles for adjunctive pain control during occupational therapy in pediatric burn patients. Cyberpsychol Behav Soc Netw. 2014;17(6):397-401.

30. Sharar SR, Miller W, Teeley A, et al. Applications of virtual reality for pain management in burn-injured patients. Expert Rev Neurother. 2008;8(11):1667-1674.

31. Das DA, Grimmer KA, Sparnon AL, McRae SE, Thomas BH. The efficacy of playing a virtual reality game in modulating pain for children with acute burn injuries: a randomized controlled trial [ISRCTN87413556]. BMC Pediatr. 2005;5(1):1.

32. Hoffman HG, Richards TL, Van Oostrom T, et al. The analgesic effects of opioids and immersive virtual reality distraction: evidence from subjective and functional brain imaging assessments. Anesth Analg. 2007;105(6): 1776-1783.

33. Kipping B, Rodger S, Miller K, Kimble RM. Virtual reality for acute pain reduction in adolescents undergoing burn wound care: a prospective randomized controlled trial. Burns. 2012;38(5):650-657.

34. Jeffs D, Dorman D, Brown S, et al. Effect of virtual reality on adolescent pain during burn wound care. J Burn Care Res. 2014;35(5):395-408.

35. Garrett B, Taverner T, Masinde W, Gromala D, Shaw C, Negraeff M. A rapid evidence assessment of immersive virtual reality as an adjunct therapy in acute pain management in clinical practice. Clin J Pain. 2014;30(12):1089-1098.

36. Dahlquist LM, Weiss KE, Law EF, et al. Effects of videogame distraction and a virtual reality type head-mounted display helmet on cold pressor pain in young elementary school-aged children. J Pediatr Psychol. 2010; 35(6):617-625.

37. Sil S, Dahlquist LM, Thompson C, et al. The effects of coping style on virtual reality enhanced videogame distraction in children undergoing cold pressor pain. J Behav Med. 2014;37(1):156-165.

38. Asl Aminabadi N, Erfanparast L, Sohrabi A, Ghertasi Oskouei S, Naghili A. The impact of virtual reality distraction on pain and anxiety during dental treatment in 4-6 year-old children: a randomized controlled clinical trial. J Dent Res Dent Clin Dent Prospects. 2012;6(4):117-124.

39. Kemp AM, Jones S, Lawson Z, Maguire SA. Patterns of burns and scalds in children. Arch Dis Child. 2014;99(4):316-321.

40. Nooij SA, Pretto P, Oberfeld D, Hecht H, Bülthoff HH. Vection is the main contributor to motion sickness induced by visual yaw rotation: Implications for conflict and eye movement theories. PLoS One. 2017;12(4):e0175305.

41. Feeley N, Cossette S, Côté J, et al. The importance of piloting an RCT intervention. Can J Nurs Res. 2009;41(2):84-99.

42. Merkel SI, Voepel-Lewis T, Shayevitz JR, Malviya S. The FLACC: a behavioral scale for scoring postoperative pain in young children. Pediatr Nurs. 1997;23(3):293-297.

43. Brouh Y, Paut O, Camboulives J, Couvely J. Évaluation de l'anxiété pré-opératoire de l'enfant par l'échelle de Smith modifiée: résultats préliminaires [Evaluation of preoperative anxiety of the child by the modified Smith scale: preliminary results]. Médecine d'Afrique Noire. 1996;43(10). French.

44. Smith RM. Anesthesia for Infant and Children. 4th ed. St. Louis, MO: CV Mosby company; 1980:87.

Journal of Pain Research

\section{Publish your work in this journal}

The Journal of Pain Research is an international, peer reviewed, open access, online journal that welcomes laboratory and clinical findings in the fields of pain research and the prevention and management of pain. Original research, reviews, symposium reports, hypothesis formation and commentaries are all considered for publication.
45. LeBaron S, Zeltzer L. Assessment of acute pain and anxiety in children and adolescents by self-reports, observer reports, and a behavior checklist. J Consult Clin Psychol. 1984;52(5):729-738.

46. Tremblay V, Khadra C, Charette S, et al. Development of a scale to measure comfort in children with burn injuries (poster). Paper presented at: 10th International Forum on Pediatric Pain; 2015; White Point Beach Resort, Nova Scotia, Canada.

47. Lancaster GA, Dodd S, Williamson PR. Design and analysis of pilot studies: recommendations for good practice. J Eval Clin Pract. 2004;10(2): 307-312.

48. Myers R, Lozenski J, Wyatt M, et al. Sedation and analgesia for dressing change: a survey of American Burn Association Burn Centers. J Burn Care Res. 2017;38(1):e48-e54.

49. Griggs C, Goverman J, Bittner EA, Levi B. Sedation and pain management in burn patients. Clin Plast Surg. 2017;44(3):535-540.

50. van der Heijden MJE, de Jong A, Rode H, Martinez R, van Dijk M. Assessing and addressing the problem of pain and distress during wound care procedures in pediatric patients with burns. Burns. Epub 2017 Aug 18.

51. Cheng JC, Bosma RL, Hemington KS, Kucyi A, Lindquist MA, Davis $\mathrm{KD}$. Slow- 5 dynamic functional connectivity reflects the capacity to sustain cognitive performance during pain. Neuroimage. 2017;157:61-68.

52. Kucyi A, Davis KD. The dynamic pain connectome. Trends Neurosci. 2015;38(2):86-95.

53. von Baeyer CL, Spagrud LJ. Systematic review of observational (behavioral) measures of pain for children and adolescents aged 3 to 18 years. Pain. 2007;127(1):140-150.

54. Blount RL, Loiselle KA. Behavioral assessment of pediatric pain. Pain Res Manag. 2009;14(1):47-52.

55. Ahola Kohut S, Pillai Riddell R. Does the neonatal facial coding system differentiate between infants experiencing pain-related and non-painrelated distress? J Pain. 2009;10(2):214-220.

56. National Scientific Council on the Developing Child. Children's Emotional Development Is Built into the Architecture of Their Brains: Working Paper No. 2. 2004 (Third printing 2011).

57. Malviya S, Voepel-Lewis T, Tait AR, Merkel S, Tremper K, Naughton N. Depth of sedation in children undergoing computed tomography: validity and reliability of the University of Michigan Sedation Scale (UMSS). Br J Anesth. 2002;88(2):241-245.

58. Maani CV, Hoffman HG, Morrow M, et al. Virtual reality pain control during burn wound debridement of combat-related burn injuries using robot-like arm mounted VR goggles. J Trauma. 2011;71(1 0): S125-S130.

59. Schmitt YS, Hoffman HG, Blough DK, et al. A randomized, controlled trial of immersive virtual reality analgesia, during physical therapy for pediatric burns. Burns. 2011;37(1):61-68.

60. Wang M, Anagnostou E. Virtual reality as treatment tool for children with Autism. In: Patel VB, Preedy VR, Martin CR, editors. Comprehensive Guide to Autism. New York, NY: Springer New York; 2014: 2125-2141.

61. Witmer BG, Singer MJ. Measuring presence in virtual environments: a presence questionnaire. Presence Teleoper Virtual Environ. 1998;7(3): $225-240$.

\section{Dovepress}

The manuscript management system is completely online and includes a very quick and fair peer-review system, which is all easy to use. Visit http://www.dovepress.com/testimonials.php to read real quotes from published authors. 